\section{$\underset{\substack{\text { hommes } \\ \text { \& migrations }}}{ }$}

\section{Hommes \& migrations}

Revue française de référence sur les dynamiques

migratoires

$1326 \mid 2019$

Londres et ses migrations

\title{
Colin MacInnes (1914-1976), emblème de la culture retro
}

\section{Lucy Robinson}

Traducteur : Vanessa Kientz

\section{OpenEdition}

\section{Journals}

\section{Édition électronique}

URL : https://journals.openedition.org/hommesmigrations/9714

DOI : 10.4000/hommesmigrations.9714

ISSN : 2262-3353

Éditeur

Musée national de l'histoire de l'immigration

Édition imprimée

Date de publication : 1 juillet 2019

Pagination : 24-25

ISBN : 978-2-919040-46-9

ISSN : 1142-852X

\section{Référence électronique}

Lucy Robinson, «Colin MacInnes (1914-1976), emblème de la culture retro », Hommes \& migrations [En ligne], 1326 | 2019, mis en ligne le 01 janvier 2019, consulté le 16 janvier 2022. URL : http:// journals.openedition.org/hommesmigrations/9714 ; DOI : https://doi.org/10.4000/

hommesmigrations.9714 


\section{Colin MacInnes \\ (1914-1976), emblème de la culture rétro}

\section{Lucy Robinson,}

professeure d'histoire, université du Sussex.

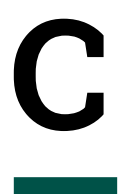

olin MacInnes a tissé les fils de la réconciliation d'après-guerre en Grande-Bretagne. Il est passé pour cela par des maisons de campagne, des bars bohémiens, des clubs afro-caribéens, le cinéma d'art et d'essai, l'anarchisme et la libération gay. Son écriture évolue également entre les genres littéraires, ciblant ainsi des publics variés... Ses articles expliquaient l'anarchisme, célébraient le National Health Service (NHS), le système de santé publique au Royaume-Uni, et faisaient éclater les contradictions qui traversaient les réformes du gouvernement. De plus, la façon dont il a évoqué sa propre sexualité fut un marqueur du changement des idées de l'époque. Il a notamment décrit en 1961 une scène d'érotisme gay dans See you at Mables, avant la décriminalisation de l'homosexualité en 1967. Il a publié un plaidoyer pour la bisexualité dans Loving them Both en 1973 et, à la fin de sa vie, collaborait de façon régulière avec Gay News.

Selon l'historien Nick Bentley, MacInnes a déplacé la frontière entre réalité et fiction. Sa fiction nous plonge au cœur des enjeux émergeant dans une société désormais en paix: le youthquake ${ }^{1}$, les préjugés raciaux, l'évolution des rôles sexuels, les nouveaux métiers et loisirs. Maclnnes a donné un sens, un cadre et une voix aux Long Sixties. Le chanteur de jazz
George Melly lui attribue la paternité de la «permissivité débridée des années soixante». Maclnnes, de son côté, a affirmé être l'inventeur du mot «teenager».

En 1959, Colin MacInnes publie le quatrième roman d'une série consacrée aux questions sociales, Absolute Beginners. Le protagoniste ne porte pas de nom. C'est un adolescent emblématique, gominé, cool et créatif. Crêpe Suzette, son ex-petite amie, est à la fois le sujet de son art et son talon d'Achille. Le roman, dont les épisodes se succèdent le temps d'un été sur fond de tensions raciales, est devenu une référence culturelle de la jeunesse dans les années 1950 et 1960.

Mais Absolute Beginners constitue aussi le premier avertissement envoyé par un roman de la fin des années 1950 à la culture rétro des années 1980. En 1986, Julien Temple adapte le livre en film musical dans lequel Patsy Kensit tient le premier rôle et où apparaissent également David Bowie, Sade et Steven Berkoff. Dans le rôle du narrateur, Patsy Kensit s'appelle Colin, comme le prénom de MacInnes qui passe

1. Le Youthquake est un mouvement culturel des années 1960 dont la particularité est de prendre la jeunesse comme source d'inspiration. Il concernait notamment la musique, la culture pop et la mode. 
ainsi du statut de témoin à celui de protagoniste. Le film montre l'émergence d'une scène anglaise jazz soul très particulière dans les années 1980, autour du Wag Club et d'artistes comme Sade, Carmel, Working Week et les Style Council de Paul Weller. Mais la production ayant rencontré des difficultés, le film n'a pas été bien accueilli.

Nous pourrions, d'autre part, être tentés de réévaluer certains travaux de Macinnes. Son fétichisme du corps masculin noir avait quelque chose à voir avec un postulat colonialiste. Ses premiers écrits au sujet de la «scène queer» étaient iconoclastes. Il a toutefois su doter toute une génération d'un vocabulaire et d'un récit commun. Grâce à lui également, la société a appris à prendre très au sérieux la musique et la mode des jeunes.

Texte traduit de l'anglais par Vanessa Kientz

\section{Bibliographie}

Nick Bentley, «"New Elizabethans": The Representation of Youth Subcultures in 1950s British Fiction », in Literature \& History, vol. 19, $n^{\circ} 1$, 2010, p. 20.

Tony Gould, Inside Outsider: The Life and Times of Colin Maclnnes, Londres, Allison \& Busby, 1993.

Stuart Hall, "Absolute Beginnings», in Universities \& Left Review, vol. 7, n²3, 1959.

Colin Maclnnes, England, Half English, New York, Random House, 1961.

Colin Maclnnes, «Learning from Gays », in Gay News, n० 72, 1972, p. 11-12.

Colin Maclnnes, Loving Them Both, Londres, Martin, Brian \& O'Keeffe, 1973.

Colin MacInnes, The Colin MacInnes Omnibus: His Three London Novels: City of Spades: Absolute Beginners: Mr Love and Justice, Londres, Allison \& Busby, 2005.

George Melly, "Death of a Rebel», in The Observer, $n^{\circ} 8,1976$.

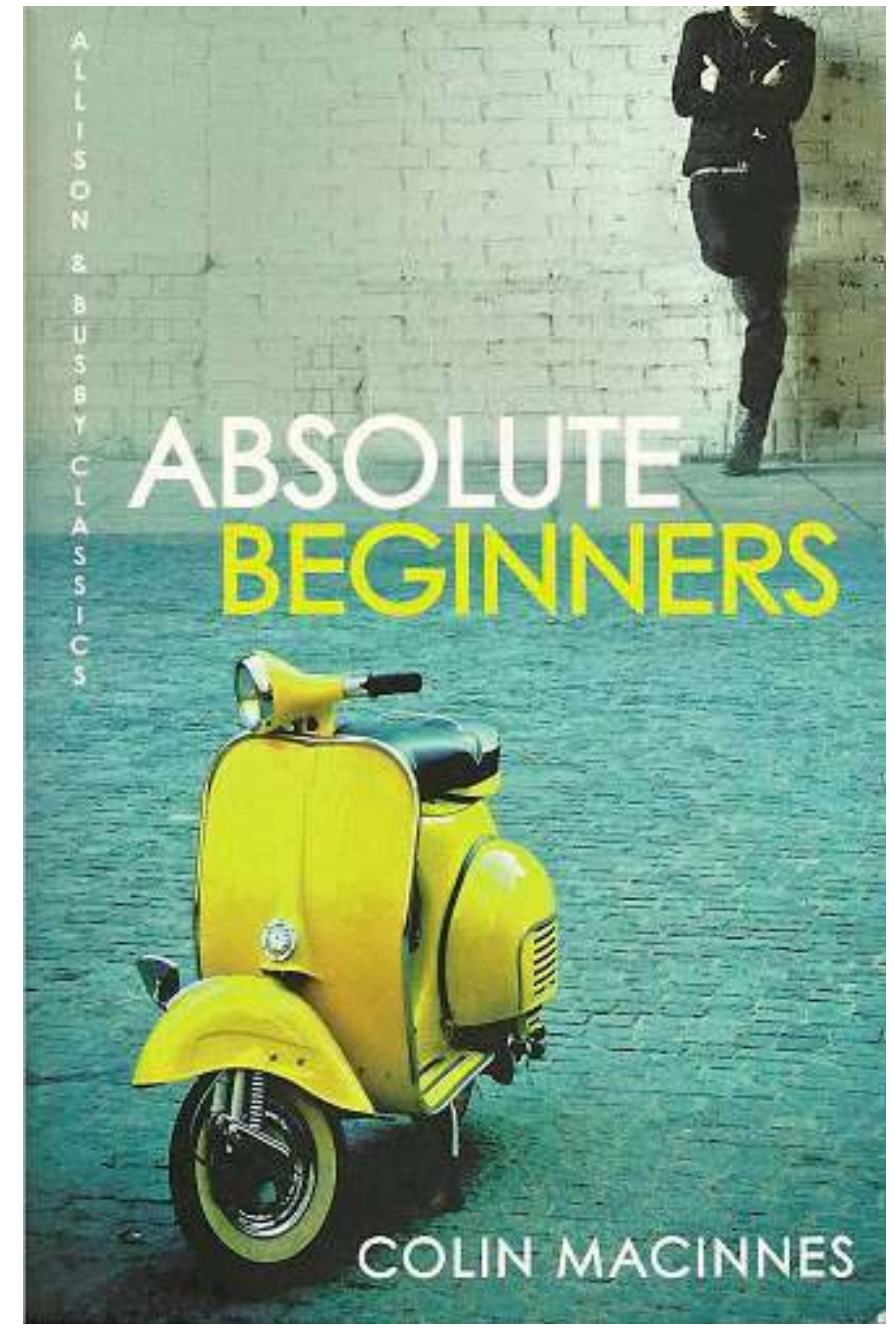

- La couverture du roman Absolute Beginners, réédité en 1986 chez Hart Davis Mac Gibbon. 